\title{
Adherence of preventive oral care products in the Syrian market to evidence-based international recommendations
}

D. Habes ${ }^{1}$, R. Mahzia ${ }^{2}$, K. Nakhleh ${ }^{3}$ and E. Joury 4,5

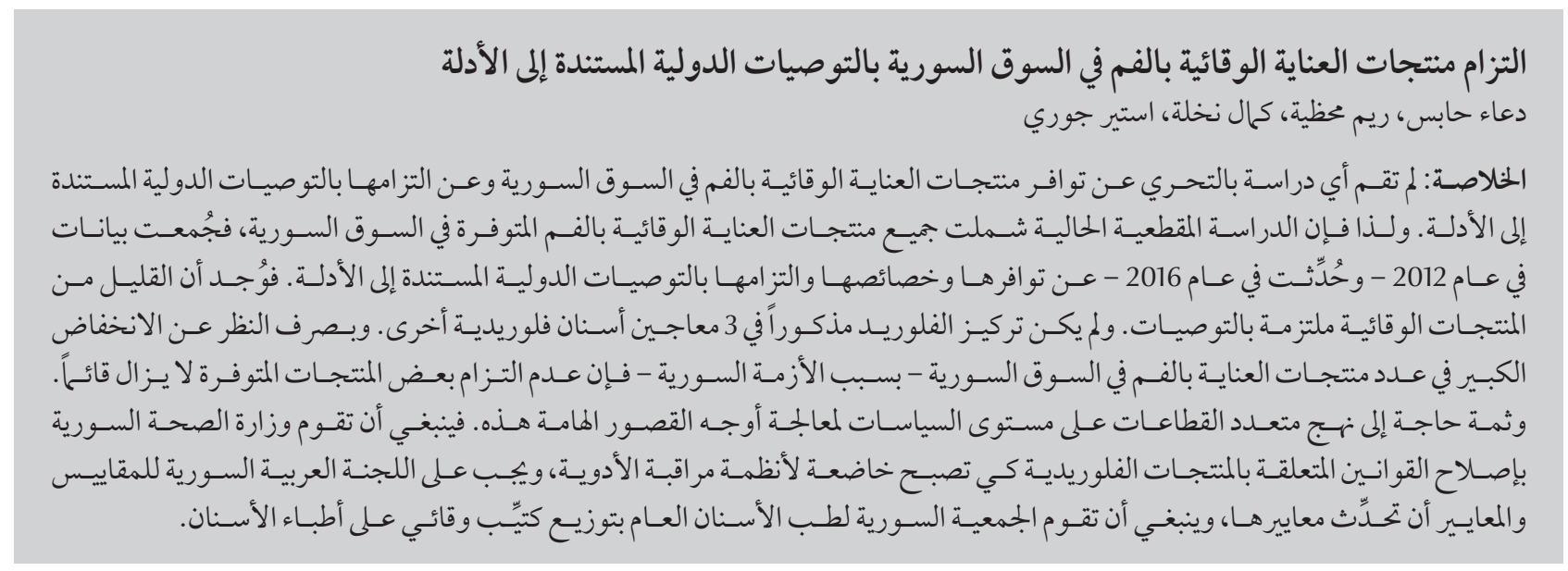

ABSTRACT No study has investigated the availability and adherence of preventive oral care products on the Syrian market to evidence-based international recommendations. Data were collected in 2012, and updated in 2016, in terms of availability, characteristics and adherence to evidence-based international recommendations. Few preventive products adhered to the recommendations. Despite the large decrease in the number of oral care products on the Syrian market, due to the Syrian crisis, nonadherence of some of the available products is still present. A multisectorial approach at a policy level is needed to address such important limitations. The Syrian Ministry of Health should reform regulations for fluoride products to become subject to drug monitoring systems; the Syrian Arab Committee for Measurements and Standards needs to update its standards; and the Syrian General Dental Association should distribute a preventive booklet to dental practitioners.

\section{Conformité des produits de soins dentaires préventifs du marché syrien avec les recommandations} internationales fondées sur des données probantes

RÉSUMÉ Aucune étude n'a examiné à ce jour la disponibilité et la conformité des produits de soins dentaires préventifs sur le marché syrien avec les recommandations internationales fondées sur des données probantes. Des données ont été collectées en 2012, et mises à jour en 2016, en ce qui concerne la disponibilité, les caractéristiques et la conformité de ces produits avec les recommandations internationales fondées sur des données probantes. Peu de produits préventifs étaient conformes aux recommandations. Malgré une forte diminution du nombre de produits de soins dentaires sur le marché syrien du fait de la crise actuelle dans le pays, la non-conformité de certains produits disponibles reste d'actualité. Une approche multisectorielle au niveau politique est nécessaire pour remédier à ces lacunes importantes. Le ministère syrien de la Santé doit réformer les réglementations existantes sur les produits à base de fluor afin que ceux-ci soient soumis à des systèmes de suivi des médicaments; le Comité arabe syrien des mesures et des normes doit mettre à jour ses normes ; et l'Association de dentisterie générale syrienne doit distribuer une plaquette de prévention à l'intention des praticiens dentaires.

'Department of Orthodontics, Faculty of Dentistry, Damascus University, Damascus, Syrian Arab Republic. ${ }^{2}$ Department of Oral Pathology, Faculty of Dentistry, Damascus University, Damascus, Syrian Arab Republic. ${ }^{3}$ Angle House Orthodontics, London, United Kingdom. ${ }^{4}$ Population and Patient Health, King's College London Dental Institute, University of London, London, United Kingdom. ${ }^{5}$ Department of Oral Medicine, Faculty of Dentistry, Damascus University, Damascus, Syrian Arab Republic (Correspondence to: easter.joury@kcl.ac.uk). 


\section{Introduction}

Preventing oral diseases in the Middle East is of paramount importance. Oral health is an essential integral part of general health and has a profound impact on individuals' wellbeing and quality of life. The Middle East countries are facing a marked increase in the prevalence and severity of dental caries and periodontal diseases (1). Furthermore, the rates of dental caries in the Eastern Mediterranean Region are higher than in most industrialized countries $(2,3)$. This relentless increase in the burden of oral diseases is observed across different age groups. Based on the $\mathrm{WHO}$ oral health data bank, the mean number of decayed, missing and filled deciduous teeth at 5 years of age in the Middle East is 5.7. There is a variation in this number across the region. For example, based on the aforementioned data bank, the mean number of decayed, missing and filled deciduous teeth is 1.7 in Saudi Arabia, 2.3-2.7 in the Syrian Arab Republic and Kuwait and 3.4 in Jordan and Lebanon (4-6). Dental caries increases with age in Middle East countries (7). More than $90 \%$ of cases of dental caries throughout the Eastern Mediterranean Region remain untreated, leading to rising rates of edentulousness in older populations (8).

The above raises serious questions about the effectiveness and appropriateness of the traditional western-style, treatment-oriented oral health strategies and approaches adopted in Middle East countries to address the burden of oral diseases. The major limitations of such strategies, particularly in relation to their ineffectiveness and high requirement for human and financial resources, emphasize the urgency of reorienting oral health services to focus on prevention to address the growing burden of oral diseases. This view was endorsed by the World Dental Federation Vision 2020 (9).

One of the essential requirements for reorienting oral health services toward prevention is providing an evidence-based preventive toolkit for clinical teams (10). Such a preventive toolkit leads to a range of positive changes in dental professional practices and allows all patients equal access to modern preventive advice and interventions and improved methods of self-care. It includes, besides evidence-based guidance for primary dental care teams, lists of available preventive oral care products, such as fluoride toothpastes, highconcentration fluoride toothpastes, mouth rinses, fluoride varnish, and pit and fissure sealants. Such products might be the only means, in the majority of Middle East countries, to fluoridate the mouth to decrease the prevalence of dental caries. Despite the effectiveness of water fluoridation in decreasing dental caries (11), it is either impractical because of the poor infrastructure for piped water supplies, or undesirable in some Middle East countries that have high levels of natural fluoride (6). For example, in the Syrian Arab Republic, the majority of areas have low fluoride content in the water $(>0.5 \mathrm{ppm})$, which is below the required level for caries prevention, whereas a few areas, such as Palmyra and Alhasaka, have elevated fluoride content (1.9 ppm) (12). Thus, it is clear that the main focus for fluoridating the mouth in the Middle East is to use the aforementioned preventive oral care products.

Developed countries, such as the United Kingdom, have developed a list of their preventive oral care products based on careful consideration of their adherence to evidence-based recommendations (10). Such a list helps dental professionals to give informed advice on preventive care and take appropriate actions. Also, the recommendations have prompted several manufacturers to reformulate their fluoride products with more effective and safe levels for caries control, and to include evidencebased labelling and instructions on how to use self-care products.
Although the above mentioned translational (applied) research is undertaken in the majority of developed countries, little has been conducted in developing countries. None of the countries in the Middle East has developed such an evidence-based preventive toolkit for oral health care. Thus, in the light of the lack of such important translational research in the Middle East, the present study aimed to investigate the availability and adherence of preventive oral care products on the Syrian market to evidence-based international recommendations.

\section{Materials and methods}

\section{Study design and preventive oral care products}

The current study adopted a crosssectional design. We investigated all preventive oral care products available on the Syrian market, including self-care and professionally applied products. Control of caries and gum disease is related to tooth brushing with fluoride toothpaste and physical removal of plaque, respectively $(13,14)$. Self-care products were manual and powered toothbrushes, interdental plaque control products (dental floss and tape and interdental brushes), toothpastes (fluoridated toothpastes, toothpastes containing ingredients that reduce plaque, gingivitis and bleeding gums, such as tin fluoride, triclosan with copolymer or zinc citrate) and mouth rinses (containing fluoride or antibacterial ingredients, such as chlorhexidine). The professionally applied preventive products included fluoride varnish/ gels, and pit and fissure sealants.

\section{Ethics and permissions}

Ethical approval and permission to conduct the study were obtained from Damascus University Faculty of Dentistry Research Ethics Committee (no 1186/2012), the Syrian Ministry of 
Health and the Syrian Directorate of Medical Supplies.

\section{Data collection}

Data were collected between February and April 2012, and updated in March 2016, on the availability and characteristics of preventive oral care products on the Syrian market (Table 1).

We did not collect data on products related to dentures/removable appliances, such as brushes, pastes, disinfectant products, adhesives, dry mouth rinses, tooth powders, desensitizing, whitening and other types of toothpastes, and anaesthetic rinses. This was because these self-care products are not related to the prevention of dental caries and gum diseases. Also, data on fluoride supplements were not collected because these are no longer internationally recommended. This was based on the conclusion of a recent systematic review of fluoride tablets, drops, lozenges and chewing gums indicating that the evidence for the effect of these additional sources of fluoride on deciduous teeth is unclear $(15)$.

\section{Data collection procedures}

A list of Syrian manufacturers and importers of preventive oral care products was prepared using the governmental records of the Syrian Ministry of Health in the Directorates of Pharmaceutical Affairs, Medical Supplies and Oral Health. Next, manufacturers and companies were contacted and asked to provide a full list of their manufactured or imported preventive oral care products. After developing an exhaustive list of oral care products available on the Syrian market, two researchers (DH and RM) undertook field visits to 36 pharmacies (including all central pharmacies in Damascus) and 12 dental supply stores to examine directly the products and extract relevant data. Relevant information was extracted from the packaging and instruction leaflets of the oral care products.

\section{Evidence-based international recommendations on preventive oral care products}

Data collected in the current study on preventive oral care products were checked against evidence-based international recommendations. The latter are summarized in Table 2.

\section{Data synthesis and analysis}

The frequency distribution of preventive oral care products was calculated. The characteristics (features, concentrations of active agents and instructions for use) of available preventive oral care products were checked against evidence-based international recommendations.

\section{Results}

There were 216 self-care and 9 professionally applied preventive products available on the Syrian market in 2012.

There were 58 manual toothbrushes available (Table 3), of which, 44 were

\begin{tabular}{|c|c|}
\hline Oral care product & Information \\
\hline Manual toothbrush & $\begin{array}{l}\text { Head size, texture type (soft, medium or hard), filament design (round/sharp end, length, } \\
\text { compaction and angulation), handle design, tooth-brushing instructions, labelling language } \\
\text { and other unique features. }\end{array}$ \\
\hline Powered toothbrush & $\begin{array}{l}\text { Filament design (round/sharp end, length, compaction and angulation), action type, } \\
\text { charging (electric or battery), tooth-brushing instructions and labelling language. }\end{array}$ \\
\hline Dental floss/tape & $\begin{array}{l}\text { Type (e.g., waxed/unwaxed, containing antibacterial agents and/or } \mathrm{NaF} \text { ), flavour, length, } \\
\text { instructions for use and labelling language. }\end{array}$ \\
\hline Interdental brush & Head shape, handle, instructions for use and labelling language. \\
\hline Toothpaste & $\begin{array}{l}\text { Active agents [e.g., fluoride ( } \mathrm{NaF} \text { and/or sodium monofluorophosphate); antibacterial } \\
\text { agents (triclosan (18))], active agent concentration, dental indications, instructions/ } \\
\text { recommendations for use (age, amount, frequency and other recommendations such as } \\
\text { need for parents'/carers' supervision (13), and caution not to rinse or lick) and labelling } \\
\text { language. }\end{array}$ \\
\hline Mouth rinse & $\begin{array}{l}\text { Active agents [e.g., fluoride ( } \mathrm{NaF} \text { and/or sodium monofluorophosphate); antibacterial } \\
\text { agents (chlorhexidine)], active agent concentration, dental indications, instructions/ } \\
\text { recommendations for use (timing and duration of application, and other recommendations } \\
\text { in terms of age-related contraindications, caution not to swallow or rinse after use and side } \\
\text { effects in case of prolonged use for }>1 \text { month) and labelling language. }\end{array}$ \\
\hline Fluoride varnish/gel & $\begin{array}{l}\text { Concentration, application duration and frequency, post-application instructions, clear } \\
\text { contraindication for use at home and labelling language. }\end{array}$ \\
\hline Pit and fissure sealant & $\begin{array}{l}\text { Polymerization method (light- or self-cured), material (resin or glass ionomer cement), } \\
\text { instructions for use and labelling language. For self-cured products, data also included } \\
\text { mixing, working and curing time. }\end{array}$ \\
\hline
\end{tabular}




\begin{tabular}{|c|c|}
\hline Oral care product & Evidence-based international recommendations \\
\hline Manual toothbrush & $\begin{array}{l}\text { Should have a small head }(19 \mathrm{~mm}) \text { and medium texture. } \\
\text { Instructions for tooth brushing should include: starting brushing as soon as teeth erupt } \\
\text { in the mouth (13); brushing teeth and gum line twice daily with a fluoridated toothpaste } \\
(13,19) \text {; brushing last thing at night and on one other occasion }(19,20) \text {; avoiding brushing } \\
\text { immediately after eating or drinking acidic food or drinks }(27) \text {; and parents' role in tooth } \\
\text { brushing for children aged up to } 7 \text { years. }\end{array}$ \\
\hline Powered toothbrush & Should have an oscillating, rotating action. \\
\hline Fluoride toothpaste & $\begin{array}{l}\text { Toothpastes containing } \mathrm{NaF} \text { are more effective in caries prevention than others containing } \\
\text { sodium monofluorophosphate (13). Fluoride concentration should be no less than } 1000 \\
\text { ppm for children aged up to } 3 \text { years }(22) \text { and } 1350-1500 \text { ppm for children aged } 3 \text { years and } \\
\text { adults (22). } \\
\text { Instructions for use should include: use of a smear of fluoride toothpaste for children } \\
\text { aged up to } 3 \text { years (23) and a pea-sized amount for children aged } 3 \text { years }(23) \text {; spitting out } \\
\text { toothpaste without rinsing the mouth with water to maintain fluoride concentration (24); } \\
\text { and not eating or licking fluoride toothpaste by children to avoid fluorosis }(23,25) \text {. }\end{array}$ \\
\hline $\begin{array}{l}\text { High-concentration fluoride } \\
\text { toothpaste }\end{array}$ & $\begin{array}{l}\text { Should be dispensed by prescription and have a concentration of } 2800 \mathrm{ppm} \text { for those } \\
\text { aged } 10 \text { years and } 5000 \mathrm{ppm} \text { for those aged } 16 \text { years }(22) \text {. }\end{array}$ \\
\hline Fluoride mouth rinse & $\begin{array}{l}\text { Daily fluoride mouth rinses should be used in children aged no less than } 8 \text { years and } \\
\text { the fluoride concentration should be } 0.05 \%(26) \text {. Instructions for use should include } \\
\text { application at different times to tooth brushing, to increase the time during which teeth are } \\
\text { exposed to fluoride }(22,26) \text {. }\end{array}$ \\
\hline Antibacterial mouth rinse & $\begin{array}{l}\text { Chlorhexidine is the most effective antibacterial agent and usually comes in concentrations } \\
\text { of } 0.2 \% \text { or } 0.12 \%(27) \text {. }\end{array}$ \\
\hline Fluoride varnish and gel & $\begin{array}{l}\text { The ideal fluoride concentration in varnish should be } 2.2 \% \text { (16). Fluoride varnish is more } \\
\text { effective in dental caries control that fluoride gel (16). }\end{array}$ \\
\hline
\end{tabular}

for adults and 14 for children. Only two of the 58 available toothbrushes adhered to evidence-based international recommendations, by having a small head and medium texture (Table 4). There were only two powered toothbrushes available and both had the required oscillating and rotating actions (Tables 3 and 4).

Both types of interdental plaque control products were available, namely, dental floss and tape (10 products) and interdental brushes (10 products) ( $\mathrm{Ta}$ ble 3).

Out of 103 available toothpastes (Table 3), only 83 contained fluoride, of which, 52 were formulated with $\mathrm{NaF}$ (the most effective form of fluoride). Furthermore, there were 22 toothpastes that contained active antibacterial agents (chlorhexidine or triclosan) and one that contained tin fluoride (Table 3).

Three fluoride toothpastes did not declare their fluoride concentration and another 22 declared their fluoride concentration in percentages, $g$ or $\mu \mathrm{g} / \mathrm{g}$ rather than ppm. Forty-three toothpastes had a fluoride concentration of 1350-1500 ppm and only three had a concentration of 1000 ppm (Table 3). None of the latter declared its exclusive indication for use in children aged up to 3 years (Table 4 ). There were 13 toothpastes that included ineffective concentrations of fluoride (i.e. $<1000$ ppm) (Table 4). Seventeen high-concentration fluoride toothpastes (>1500 ppm) were available, of which, only sixhad the recommended concentration (2800-5000 ppm) of fluoride and two exceeded the maximum recommended concentration (>5000 ppm). All 17 of these toothpastes were potentially toxic for children as they were indicated for daily use for all ages, including children younger than the evidence-based recommended age for use (Table 4).

Several fluoride toothpastes included instructions that contradicted the evidence-based recommendations. For example, the instructions for six fluoride toothpastes recommended rinsing the mouth with water after use. The instructions for three toothpastes with 1000 ppm fluoride recommended use in children aged more than 3 years (Table 4). In contrast, few fluoride toothpastes included instructions for use that were coherent with evidence-based recommendations. For example, 28 and 25 fluoride toothpastes recommended the use of a smear or pea-sized amount of toothpaste and parent supervision, respectively. Also, the instructions for seven toothpastes recommended not swallowing the toothpaste. For labelling language, 11 toothpaste instructions did not use Arabic.

There were 33 mouth rinses available (Table 3 ). Fifteen mouth rinses contained fluoride, of which, nine were formulated with $\mathrm{NaF}$. Seven of the 18 antibacterial mouth rinses contained chlorhexidine. Fourteen fluoride mouth rinses included instructions that contradicted evidence-based recommendations, namely, use after tooth brushing 
(11 products) and rinsing with water after use (three products). Although 16 mouth rinses included a clear contraindication for use in children aged up to 6 years, 15 did not include such a clear contraindication (Table 4), and another six products did not use Arabic in their instructions for use.

Finally, with respect to professionally applied preventive care products, there were three fluoride gel products and six pit and fissure sealants. No fluoride varnish was available. One of the available fluoride gels was potentially toxic for children, as it was recommended for home use and its instructions included the use of fluoride trays (plastic trays to be filled with fluoride gel). All the available fluoride gels had fluoride concentrations less than the recommended level (2.2\%) (Table 4).

The updated data in 2016 showed a large decrease in the number of oral care products available on the Syrian market. Nevertheless, nonadherence of some of the available products was still present (Tables 3 and 4).

\section{Discussion}

This is believed to be the first study in the Middle East to investigate the availability and adherence of preventive oral care products to evidence-based international recommendations. The present study was conducted on preventive oral care products available on the Syrian market. The findings indicate that products that adhered to evidence-based recommendations were either few in number or not available. For example, out of 58 manual toothbrushes, there were only two that had recommended features. Also, while three fluoride gels were available, no fluoride varnish was found. The latter is more effective than the former for prevention of dental caries (16).

The most worrying findings were the fluoride concentration and instructions for use in a number of fluoride

\begin{tabular}{lcc}
\hline $\begin{array}{l}\text { Table } 3 \text { Availability of preventive oral care products on the Syrian market in 2012 } \\
\text { and } 2016\end{array}$ & \multicolumn{2}{c}{ Frequency } \\
\hline Oral care product & $\mathbf{2 0 1 2}$ & $\mathbf{2 0 1 6}$ \\
& 58 & 31 \\
Manual toothbrush & 2 & 2 \\
Powered toothbrush & 10 & 6 \\
Dental floss/tape & 10 & 4 \\
Interdental brush & 83 & 35 \\
Fluoride toothpaste (all concentrations) & 3 & 2 \\
Fluoride toothpaste (1000 ppm) & 43 & 23 \\
Fluoride toothpaste (1350-1500 ppm) & 17 & 4 \\
High-concentration fluoride toothpaste & 22 & 12 \\
Chlorhexidine or triclosan toothpaste & 1 & 0 \\
Tin fluoride toothpaste & 15 & 6 \\
Fluoride mouth rinse & 18 & 13 \\
Antibacterial mouth rinse & 0 & 0 \\
Fluoride varnish & 3 & 3 \\
Fluoride gel & 5 & 2 \\
Glass ionomer cement sealant & 1 & 1 \\
Resin sealant & & \\
\hline
\end{tabular}

toothpastes. Several products had fluoride concentrations that were low and thus ineffective in caries prevention, or high with potential long-term toxic effects in children. For example, 13 fluoride toothpastes claimed to have anticaries effects although they had fluoride concentrations $<1000 \mathrm{ppm}$. Another three 1000-ppm fluoride toothpastes claimed to have anti-caries effects in children aged more than 3 years. Furthermore, 17 high-concentration fluoride toothpastes were available for purchase without prescription and had instructions for use in children younger than the safe evidence-based recommended age. The daily use of such highconcentration fluoride toothpastes, particularly among young children, could have long-term toxic effects, such as, enamel and skeletal fluorosis. Other potential sources for such toxic effects of fluoride were: fluoride mouth rinses, of which, 15 did not mention their contraindication for use in children aged less than 6 years; and fluoride gels, of which, one included instructions for use at home with special trays. Fluoride gels should be professionally applied, in small amounts, using special brushes (10). Three toothpastes did not also adhere to evidence-based recommendations by not declaring their fluoride concentrations. This is consistent with the findings of van Loverern et al. (17). They reported that many fluoride toothpaste products available in countries without established market economies, such as the Syrian Arab Republic, have unclear labelling concerning the type and concentration of fluoride. That study also showed that the concentration of free (active) fluoride in many toothpastes available on the Syrian market is far below the concentration that is declared on the products. This suggests that although some of the toothpastes currently available on the Syrian market claim to adhere to international evidence-based recommendations for concentration of fluoride, in practice, they may not.

Comparing the current study with other published studies is not easy. This is due to the paucity of published literature on the availability and adherence of oral care products available on the market to evidence-based international 


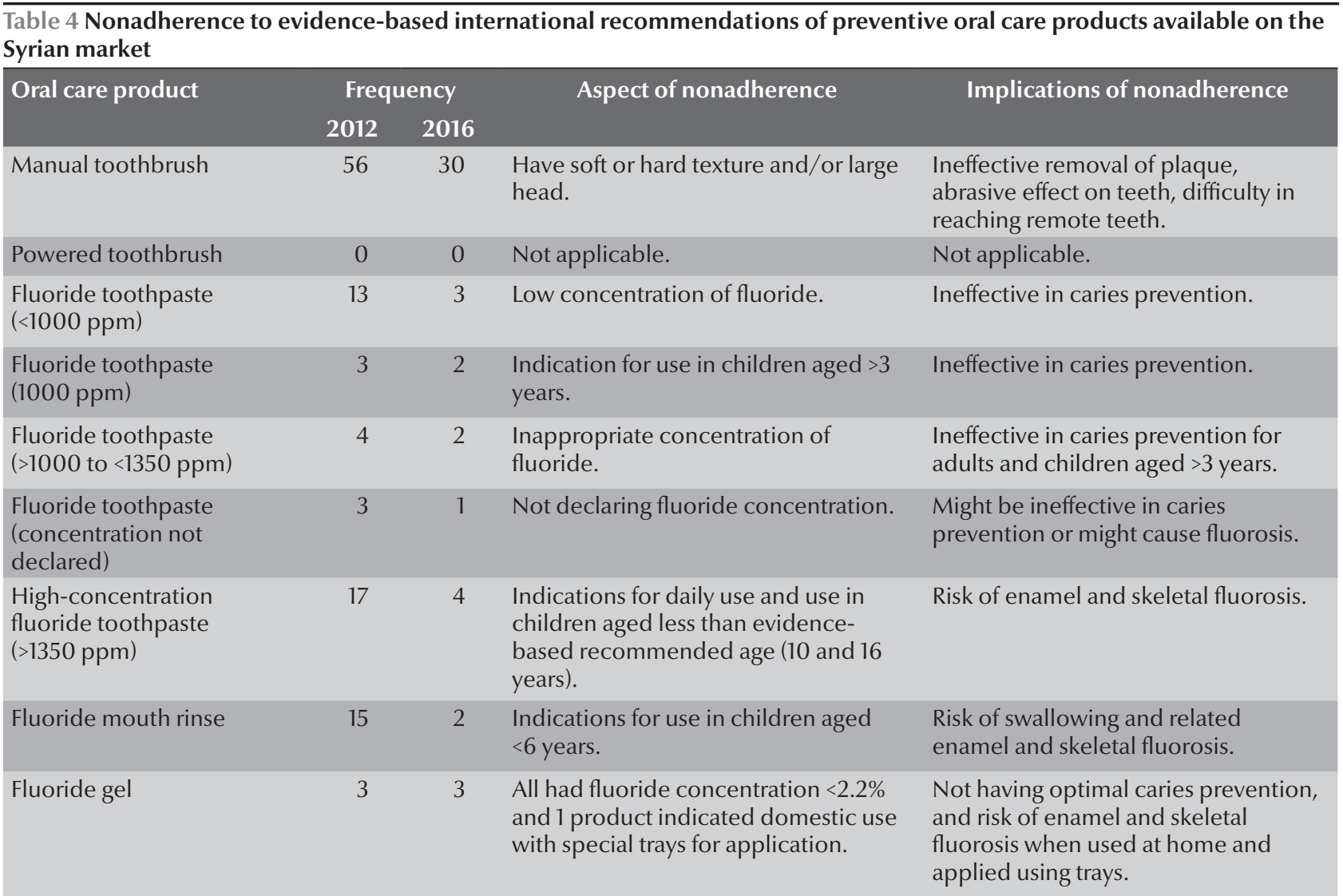

recommendations. To the best of our knowledge, the only published study is from the United Kingdom (published in 2009 and updated in 2014) (10). The United Kingdom applies strict measures to the oral care products available on its market, thus, all oral care products listed in that study were adherent to evidencebased international recommendations.

Despite the recent decrease in the number of oral care products available on the Syrian market, due to the current political crisis in the country, some of the available products are still nonadherent.

Based on the findings of the current study, it is clear that the Syrian Ministry of Health should review its regulations and carry out necessary reforms for fluoride toothpastes, rinses and gels so that they become subject to drug monitoring systems. Also, because several preventive care products include instructions for use that contradict the evidence-based recommendations, the Syrian Arab Committee for Measurements and Standards should update its standards using current evidence-based international recommendations. The latest update took place in 1995.

Effective communication should be established so that Syrian manufacturers reformulate their preventive oral care products to have evidence-based effective and safe fluoride concentrations, labelling and instructions for use. They should also be encouraged to produce fluoride varnish. In addition, strict regulations should be imposed on imported preventive oral care products. All available self-care products should have instructions for use written in Arabic, so they can be read and understood by Syrian consumers.

Data collected in the current study were arranged in a user-friendly booklet to assist Syrian general dental practitioners implement evidence-informed preventive care. Similar to developed countries, such a booklet should be adopted by the Syrian General Dental Association and distributed to general dental practitioners.
In conclusion, few oral preventive products available on the Syrian market adhered to evidence-based international recommendations. Fluoride varnish was not available. Some fluoride products (30 toothpastes and three gels) had fluoride concentrations that were low and thus ineffective in caries prevention, or high, with potential long-term toxic effects in children. Another three fluoride toothpastes did not declare their fluoride concentration. A multisectorial approach is needed to address such important limitations at a policy level. The Syrian Ministry of Health should reform regulations for fluoride products to become subject to drug monitoring systems; the Syrian Arab Committee for Measurements and Standards needs to update its standards; and the Syrian General Dental Association should distribute a booklet for preventive care to dental practitioners.

\section{Funding: None.}

Competing interests: None declared. 


\section{References}

1. Abid A, Maatouk F, Berrezouga L, Azodo C, Uti O, El-Shamy $\mathrm{H}$, et al. Prevalence and severity of oral diseases in the Africa and Middle East region. Adv Dent Res. 2015 Jul;27(1):10-7. PMID:26101335

2. Al Agili DE. A systematic review of population-based dental caries studies among children in Saudi Arabia. Saudi Dent J. 2013 Jan;25(1):3-11. PMID:23960549

3. Behbehani JM. Faculty of Dentistry, Kuwait University, designated as a World Health Organization Collaborating Centre for Primary Oral Health Care. Med Princ Pract. 2014;23 Suppl 1:10-6. PMID:24504110

4. Global oral health data bank. Geneva: World Health Organization; 2013 (http://www.who.int/oral_health/databases/ global/en/, accessed 7 November 2015).

5. Data and statistics: WHO. Geneva: World Health Organization; 2014 (http://www.emro.who.int/data-and-statistics. html, accessed 7 November 2015).

6. Sheiham A, Williams DM. Reducing inequalities in oral health in the Africa and Middle East region. Adv Dent Res. 2015 Jul;27(1):4-9. PMID:26101334

7. Bernabé $E$, Sheiham A. Extent of differences in dental caries in permanent teeth between childhood and adulthood in 26 countries. Int Dent J. 2014 Oct;64(5):241-5. PMID:24863963

8. Williams DM, Sheiham A, Honkala E. Addressing oral health inequalities in the Africa and Middle East Region. J Dent Res. 2015 Jul;94(7):875-7. PMID:26101232

9. Glick M, Monteiro da Silva O, Seeberger GK, Xu T, Pucca G, Williams DM, et al. FDI Vision 2020: shaping the future of oral health. Int Dent J. 2012 Dec;62(6):278-91. PMID:23252585

10. Delivering better oral health: an evidence-based toolkit for prevention, 3rd edition. London: Department of Health and
British Association for the Study of Community Dentistry; 2014 (https://www.gov.uk/government/uploads/system/ uploads/attachment_data/file/367563/DBOHv32014OCTMainDocument_3.pdf, accessed 26 October 2015)

11. Iheozor-Ejiofor Z, Worthington HV, Walsh T, O'Malley L, Clarkson JE, Macey R, Alam R, Tugwell P, Welch V, Glenny AM. Water fluoridation for the prevention of dental caries. Cochrane Database Syst Rev. 2015;18;6:CD010856.

12. Beiruti N, Menghini G, Taifour D. Study on the fluoride in drinking water in Syria. Syrian J Stomatol. 1999;35:62-70.

13. Marinho VCC, Higgins JPT, Sheiham A, Logan S. Fluoride toothpastes for preventing dental caries in children and adolescents. Cochrane Database Syst Rev. 2003;(1):CD002278. PMID:12535435

14. Lang NP, Schätzle MA, Löe H. Gingivitis as a risk factor in periodontal disease. J Clin Periodontol. 2009 Jul;36 Suppl 10:3-8. PMID:19432625

15. Tubert-Jeannin S, Auclair C, Amsallem E, Tramini P, Gerbaud L, Ruffieux C, et al. Fluoride supplements (tablets, drops, lozenges or chewing gums) for preventing dental caries in children. Cochrane Database Syst Rev. 2011 Dec 7;(12):CD007592. PMID:22161414

16. Wong MCM, Glenny AM, Tsang BWK, Lo ECM, Worthington HV, Marinho VCC. Topical fluoride as a cause of dental fluorosis in children. Cochrane Database Syst Rev. 2010 Jan 20;(1):CD007693. PMID:20091645

17. van Loveren C, Moorer WR, Buijs MJ, van Palenstein Helderman WH. Total and free fluoride in toothpastes from some non-established market economy countries. Caries Res. 2005 May-Jun;39(3):224-30. PMID:15914985 